\title{
PRODUÇÃo E TOLERÂNCIA À SECA DE CAFEEIROS (1)
}

\author{
- PAULO MAZZAFERA $\left({ }^{2}, 3\right)$ e ALCIDES CARVALHO $\left(^{2}\right)$
}

\begin{abstract}
RESUMO
Avaliaram-se dois experimentos de progênies instalados no Centro Experimental de Campinas (Instituto Agronômico), contendo híbridos entre introduções da índia e da África, com linhagens dos cultivares Catuaí e Mundo Novo de Coffea arabica L. Apresentaram-se dados de treze anos de produção e de quatro anos, não consecutivos, de observaçōes visuais de campo, em relação à tolerância à seca: as introduções C 1110-10 (cultivar BA-10, da india), C 1120-16 (cultivar X321, da Tanzânia) e C 1521-2 (cultivar BE-5, da Costa Rica) destacaram-se como as mais promissoras para fins de seleção de cafeeiros tolerantes à seca. Salientou-se, também, que é importante o acúmulo de informaçōes sobre produtividade, pois algumas progênies pouco produtivas se mostraram tolerantes à seca. Outros experimentos, com progênies originadas de cafeeiros dos experimentos anteriores, foram avaliados quanto à produção.
\end{abstract}

Termos de indexaçāo: cafeeiro, Coffea arabica L., tolerância à seca, progênies.

(1) Recebido para publicação em 17 de fevereiro de 1987.

(2) Seção de Genética, Instituto Agronômico (IAC), Caixa Postal 28, 13001 Campinas(SP).

(3) Bolsista da Fundação Museu do Café, Campinas(SP). 


\section{INTRODUÇÃO}

Segundo BOYER (1982), entre os vários fatores limitantes da produção vegetal, o deficit hídrico ocupa posição de destaque, pois, além de afetar diretamente as relações hídricas nas plantas, alterando-lhes o metabolismo, é fenômeno que ocorre em grandes extensōes de áreas cultiváveis. Portanto, de acordo com esse autor, as plantas parecem ter desenvolvido mecanismos capazes de diminuir os efeitos da falta de água no solo, que podem ser transmitidos geneticamente.

A comparação entre os parâmetros do balanço hídrico (THORNTWAITE \& MATHER, 1955), de várias áreas produtoras de café no Brasil levaram ORTOLANI et al. (1970) a afirmar que deficiências hídricas no solo maiores do que $150 \mathrm{~mm}$ podem afetar, drasticamente, a produção de Coffea arabica.

Considerando-se que a cafeicultura, não só em São Paulo como em outros Estados, estende-se atualmente a regiōes com variados tipos de balanço hídrico, o estabelecimento e o estudo de parâmetros para a obtenção de cafeeiros tolerantes à seca tornam-se prioritários.

Estudos têm sido feitos comparando piantas do gênero Coffea em relação ao seu comportamento mediante estresse hídrico. Para tal fim, diferentes parâmetros foram avaliados, podendo ser citados o potencial da água e osmótico na folha, condutância estomática (GOLBERT et al., 1984, e JOSIS et al., 1983), atividade da redutase de nitrato (MEGURO \& MAGALHÃES, 1983), temperatura da cobertura foliar (OROZCO-CASTAÑO \& JARAMLLO-ROBLEDO, 1978), sistema radicular (MAZZAFERA, 1984, e RAMOS, 1980) e prolina (MAZZAFERA et al., 1986). No entanto, apesar de tais estudos terem utilizado plantas de café que diferiram quanto à produtividade, comentaram pouco a relação entre a produtividade e a tolerância à seca observada através dos parâmetros analisados.

Essa consideração assume importância, em vista de que, nos vários tipos de vegetação encontrados na natureza, a produtividade é considerada mais intimamente relacionada com a água disponivel para as plantas do que qualquer outro fator ambiental (SALISBURY \& ROSS, 1978). Portanto, a capacidade das plantas em se manterem túrgidas é tida como uma característica necessária para a garantia da produção, em locais onde ocorre o deficit hídrico.

Em 1953 e 1967, a Seção de Genética recebeu, através do Departamento de Agricultura dos Estados Unidos e da Costa Rica, respectivamente, mudas de café que vieram ampliar o banco de germoplasma de espécies e cultivares existentes. As mudas oriundas dos Estados Unidos foram obtidas a partir de sementes coletadas em uma coleçăo de cafeeiros de Quênia, de várias procedências (Índia e países da África). O material de Costa Rica originou-se de sementes coletadas na Etiópia. Os principais objetivos de estudo nessas introdu- 
ções eram relativos à sua adaptação e, principalmente, à resistência à ferrugem. Entretanto, em 1971, após um longo período de estiagem, verificou-se que alguns híbridos entre essas plantas e cultivares Mundo Novo e Catuaí Vermelho de Coffea arabica, instalados em experimentos no Centro Experimental de Campinas, apresentavam-se com bom aspecto vegetativo, em comparação a outros cafeeiros que se ressentiam da deficiência hídrica. A partir de entāo, em anos subseqüentes em que tal anomalia climática ocorreu, afetando o estado de hidratação das plantas, fizeram-se observações de campo sobre o seu comportamento.

No presente trabalho procurou-se avaliar e correlacionar a produção dos çafeeiros $\theta$ a tolerância à seca, observações essas que se relacionam ao projeto de melhoramento do cafeeiro visando à resistência a condições adversas do ambitente, em realização há anos na Seção de Genética.

\section{MATERIAL E MÉTODOS}

Analisaram-se os híbridos $F_{1}$ e os seus progenitores, plantados nos ensaios de prefixos EP 131 e EP 132, com delineamento em blocos ao acaso, nove e seis repetições, respectivamente, e parcelas de uma única planta. No EP 131 foram plantados os híbridos de Catuaí Vermelho com o material oriundo da África e Índia e, ne EP 132, os hibridos entre esses materiais e o cultivar Mundo Novo.

As observações de campo sobre a tolerância à seca foram realizadas, atribuindo-se pontos, em uma escala de 1 (murcha severa) a 10 (turgescência), sendo necessário que se fizesse, antẹs do início das observaçōes, uma avaliação geral dos experimentos para $\theta$ estabelecimento de uma visão crítica do estado de hidratação das plantas.

No cafeeiro, os sintomas ocasionados pela baixa disponibilidade de água no solo mostram-se, inicialmente, pelo murchamento das folhas da porção apical da planta, zona de ativo crescimento. Com o aumento do deficit hidrico, as folhas mais jovens dẹs ramọs da porção inferior também tendem a murchar, e, em seguida, as folhas adultas e velhas pendem acentuadamente em direçāo ao solo, mostrando os bordos mais ondulados que o normal. Em um estádio mais avançado, a falta de água leva as folhas a apresentar certo grau de enrolamento, paralelo à nervura central, $O$, desfellhamenento ocorre apenas quando a seca é muito acentuada. Tais sintomas, he entanto, năo são distintamente evidentes em condições de campe, onde ecerfe sobreposição das etapas descritas. Assim, torna-se difícil a adeção de um critério preciso de avaliação com base em uma escala de pontos que corresponda especifiçamente aos estádios observados. Portanto, a distribuiçăo dos pentes pelo eritério aqui proposto necessita, indiscutivelmente, de uma visão geral e crítica do material a avaliar, assim como do bom senso e da 
experiência prática do avaliador. É necessário salientar que, para determinado periodo de estresse hídrico, deve ser feito o maior número possivel de observações, com intervalos pouco espaçados entre cada uma.

Apesar de o método de avaliaçäo visual de plantas tolerantes à seca ser empírico, ele tem sido considerado bastante satisfatório para indicar o estado de hidratação de plantas em algumas culturas, mostrando correlaçōes altamente positivas quando comparado com outras metodologias propostas mais sofisticadas (JONES, 1979, e O'TOOLE et al., 1984).

Os dados de produção, expressos em quilograma de café cereja, foram obtidos pela colheita individual das plantas, de 1974 a 1986.

Outros experimentos instalados no Centro Experimental de Campinas, que continham progênies derivadas de plantas do EP 131 e EP 132, também foram analisados quanto à produção; não toram avaliados quanto à tolerância à seca por não terem sido observados quanto a esta característica. O EP 260 foi instalado em 1978, segundo o delineamento de blocos ao acaso, com oito repetiçōes e uma planta por parcela.

Nos resultados de produção desses experimentos, somente foram relacionadas as progênies oriundas de plantas do EP 131, EP 132 e outras consideradas de interesse para a discussão geral dos dados. Entretanto, apresentou-se sua posição em relação a todas as progênies de cada experimento.

Decidiu-se pela inclusão dos resultados de produção do EP 260 , EP 237A e EP 237B neste estudo, a fim de verificar a capacidade produtiva das progênies consideradas de interesse, as quais tiveram seus progenitores avaliados quanto à tolerância à seca.

Procurou-se verificar uma possivel relação entre produção e tolerância à seca, agrupando-se, dentro dos ensaios EP 131 e EP 132, as plantas de progê nies que se mostraram produtivas e tolerantes ou pouco produtivas e tolerantes, fazendo-se a análise de correlação entre estes dados, dentro de cada grupo.

O quadro 1 apresenta os cafeeiros envolvidos na origem das progênies analisadas, assim como a sua procedência.

\section{RESULTADOS E DISCUSSÃO}

Nos experimentos EP 131 e 132 - Quadros 2 e 3 respectivamente - observou-se que em relação às avaliaçōes de tolerância à seca, destacaram-se os híbridos originados de cruzamentos entre material proveniente da Africa e Índia. No EP 131 destacou-se o hibrido $\mathrm{H} 8089$, vindo a seguir os hibridos $\mathrm{H} 8114$ e H 8130. Nesse experimento, verificou-se que o 'Catuai Vermelho' ( $\mathrm{CH}$ 2077-2-5-81) apresentou valores altos de tolerância à seca, confirmando, de certo modo, os dados de JOSIS et al. (1983), que indicaram ter esse cultivar certo nivel de tole- 
rância ao deficit hídrico no solo. No EP 132, destacaram-se H 8421 e H 8141 . A testemunha Acaiá (CP 474-7) posicionou-se entre as progênies mais suscetiveis.

Devido ao diferente número de repetições dos experimentos, não se fez a comparação entre ambos, porém, em um julgamento prévio, pode-se inferir que o Catuaí Vermeiho parece suportar melhor a falta de água no solo do que o Mundo Novo.

QUADRO 1. Procedência das introduções e cultivares de Coffea arabica envolvidos na origem das progênies dos experimentos EP 131, EP 132, EP 260, EP 237A e EP 237B, instalados no Centro Experimental de Campinas

Identificação

Origem

$\begin{array}{llll}\text { C } 500 & \text { Coffea arabica } & \text { var. Erecta } & \text { Brasil, Campinas } \\ \text { C } 566 & \text { Coffea arabica } & \text { var. Erecta } & \text { Brasil, Campinas } \\ \text { C } 1107 & \text { Coffea arabica } & \text { cv. BA-21 } & \text { India, Balehonnur } \\ \text { C } 1109 & \text { Coffea arabica } & \text { cv. BA-8 } & \text { Índia, Balehonnur } \\ \text { C } 1110 & \text { Coffea arabica } & \text { cv. BA-10 } & \text { india, Balehonnur } \\ \text { C } 1120 & \text { Coffea arabica } & \text { cv. X321 } & \text { Tanzânia } \\ \text { C } 1125 & \text { Coffea arabica } & \text { cv. Cioiccie } & \text { Etiópia } \\ \text { C } 1133 & \text { Coffea arabica } & \text { cv. Harar } & \text { Etiópia, Harar } \\ \text { C } 1137 & \text { Coffea arabica } & \text { cv. Geisha } & \text { Etiópia } \\ \text { C } 1475 & \text { Coffea arabica } & \text { cv. Cioiccie } & \text { Costa Rica } \\ \text { C } 1517 & \text { Coffea arabica } & \text { cv. 12 Kaffa } & \text { Costa Rica } \\ \text { C 1518 } & \text { Coffea arabica } & \text { cv. 333 } & \text { Costa Rica } \\ \text { C 1521 } & \text { Coffea arabica } & \text { cv. BE-5 } & \text { Costa Rica } \\ \text { H 2077-2-5-24 } & \text { Coffea arabica } & \text { cv. Catuaí Vermelho } & \text { Brasil, Campinas } \\ \text { H 2077-2-5-81 } & \text { Coffea arabica } & \text { cv. Catuaí Vermelho } & \text { Brasil, Campinas } \\ \text { CP 382 } & \text { Coffea arabica } & \text { cv. Mundo Novo } & \text { Brasil, Campinas } \\ \text { CP 467 } & \text { Coffea arabica } & \text { cv. Mundo Novo } & \text { Brasil, Campinas } \\ \text { CP 471 } & \text { Coffea arabica } & \text { cv. Mundo Novo } & \text { Brasil, Campinas } \\ \text { CP 474 } & \text { Coffea arabica } & \text { cv. Acaiá } & \text { Brasil, Campinas } \\ \text { CP 475 } & \text { Coffea arabica } & \text { cv. Mundo Novo } & \text { Brasil, Campinas } \\ \text { CMP 386-2-4-9 } & \text { Coffea arabica } & \text { cv. Mundo Novo } & \text { Brasil, Campinas } \\ \text { CMP 387-17 } & \text { Coffea arabica } & \text { cv. Mundo Novo } & \text { Brasil, Campinas }\end{array}$




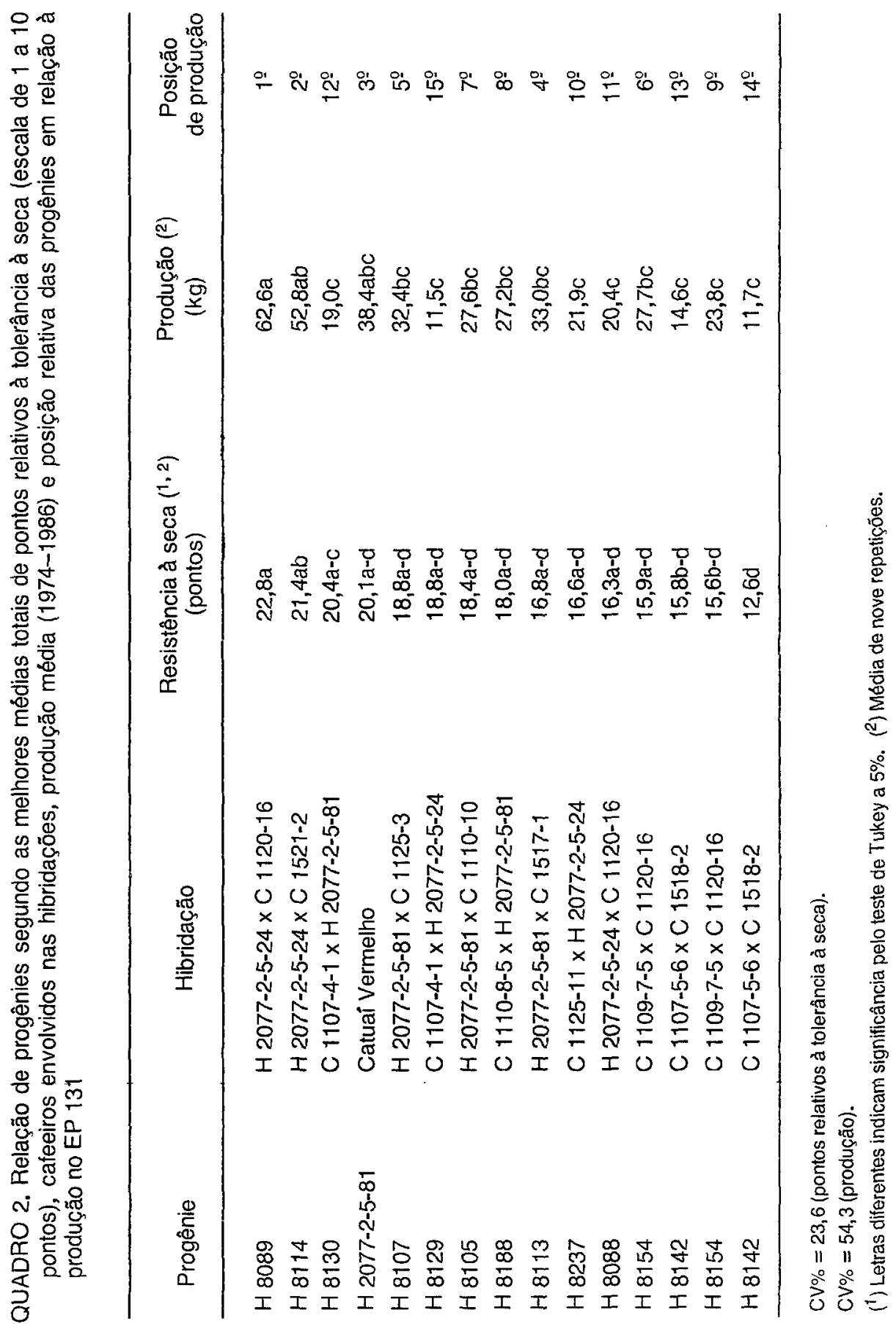




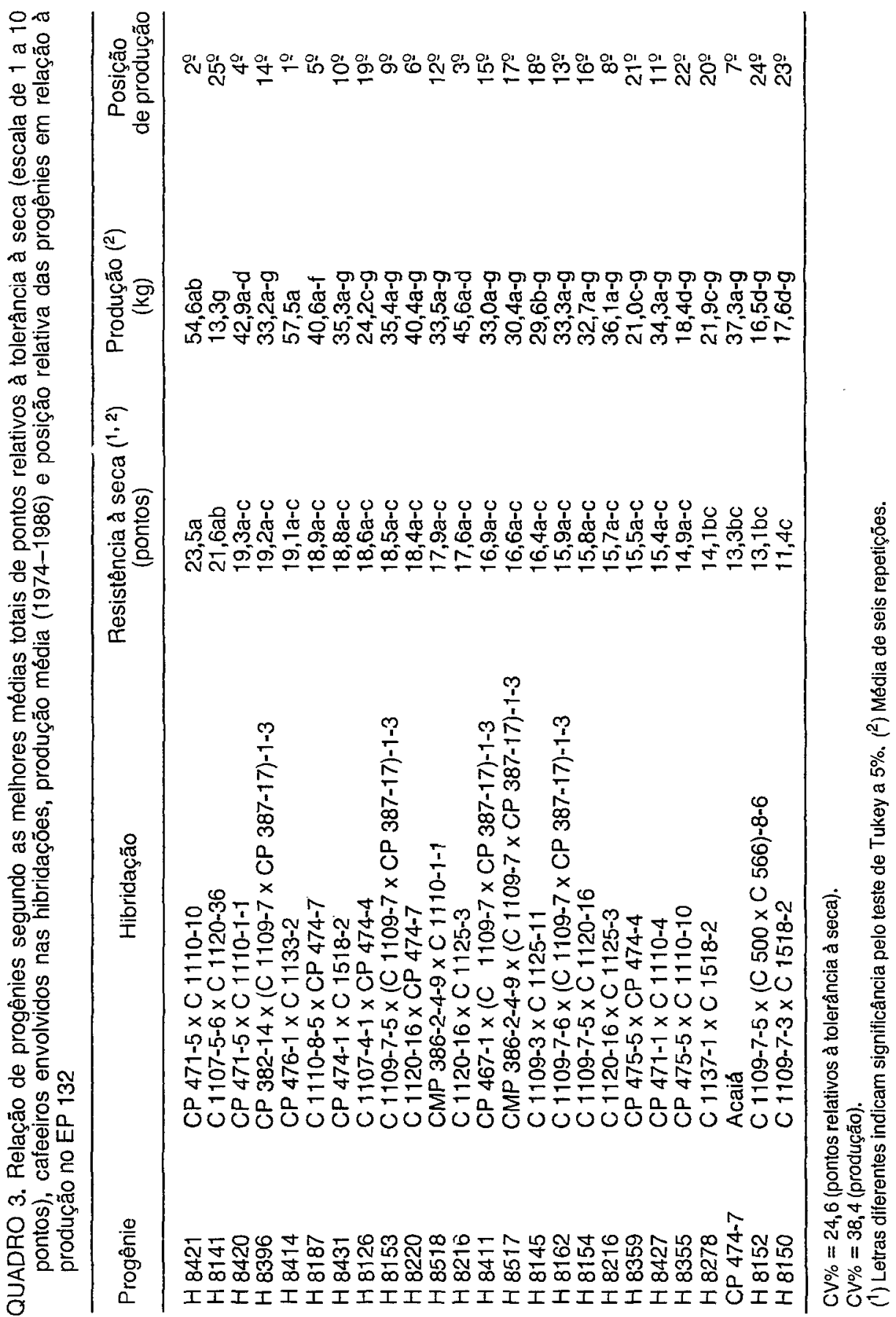


Nos quadros 2 e 3 encontram-se, também, os dados de produção dos dois experimentos. No EP 131 destacaram-se os hibridos $\mathrm{H} 8089$ e H 8114, com produçōes totais médias de nove repetições, em treze anos, de 62,6 e $52,8 \mathrm{~kg}$, respectivamente, de café cereja. A testemunha, Catuai Vermelho, aparece, em seguida, com 38,4 kg. Para O EP 132, destacaram-se os hibridos H 8414 e $\mathrm{H} 8421$, com produção de 57,5 e $54,6 \mathrm{~kg}$ respectivamente, para o mesmo periodo. A testemunha, Acaiá, teve produção de $37,3 \mathrm{~kg}$, permanecendo na sétima posição em relação à produção.

Da observação conjunta dos dados de produção e iolerância à seca dos ensaios EP 131 e EP 132, poder-se-ia inferir que as melhores combinações ocorreram entre os cultivares $C$ 1110-10 e Mundo Novo CP 471-5, e entre os cultivares $\mathrm{C} 1521-2$ e C 1120-16 e Catuaí Vermelho $\mathrm{CH}$ 2077-2-5-81. Para corroborar essa inferência, pode-se notar que os híbridos $\mathrm{H} 8105, \mathrm{H} 8188, \mathrm{H} 8088$ e H 8130 , do EP 131, diferem dos híbridos $H$ 8421, H 8187, H 8220 e H 8126, do EP 132, respectivamente, quanto ao emprego de Catuaí Vermelho ou Mundo Novo nas hibridaçōes. Dessa forma, H 8105 e H 8421 mostram que, segundo os maiores pontos de tolerância à seca e maiores produções, a introdução $C$ 1110-10 parece combinar-se melhor com Mundo Novo. Para os hibridos H 8188 e H 8187, que envolvem o cafeeiro $C$ 1110-8-5, e $\mathrm{Hi} 8130$ e $\mathrm{H}$ 8126, que envolvem a planta $C$ 1107-4-1, a melhor combinaçăo ocorreu com o Catuai Vermelho $\mathrm{CH}$ 2077-2-5-81. Os hibridos H 8088 e H 8220, que envolvem C 1120-16, parecem não mostrar boa combinação com o Acaiá C 474-4 e Catuaí CH 2077-2-5-24.

Ainda pela observação conjunta dos quadros 2 e 3 , nota-se que, no EF 131, os híbridos H 8089 e 8114 destacaram-se entre os melhores, em relação à produção e à tolerância à seca. No entanto, os híbridos $\mathrm{H} 8130$ e H 8129, resultantes de hibridações entre Catuaí Vermelho e C 1107-4-1, não tiveram o mesmo comportamento, ou melhor, mostraram-se tolerantes à seca, mas com baixa produção. Semelhantemente, para o EP 132, nota-se que alguns hibridos que se mostraram mais tolerantes à seca, como H 8421 e H 8420, permaneceram entre os mais produtivos, enquanto os híbridos de Mundo Novo com a introdução C 1107-4-1 se revelaram tolerantes à deficiência hidrica ( $H 8141$ e $H$ 8396), porém pouco produtivos.

Da análise de correlações entre os dados de produção e tolerância à seca destes híbridos, observou-se uma aparente tendência de as plantas produtivas se posicionarem entre as mais tolerantes à seca. Dessa forma, a correlação entre os dados de produção e tolerância à seca dos híbridos $\mathrm{H} 8089$ e H 8114, do EP 131 (tolerantes e produtivos), quando analisados conjuntamente, determinou $r=0,57(p=0,05)$, enquanto para os hibridos H 8129 e H 8130 (tolerantes e pouco produtivos) determinou $r=0,31$ (não significativo). No EP 132, os dados dos híbridos $\mathrm{H} 8420$ e H 8421 (tolerantes e produtivos) apresentaram valor de $r=0,45(p=0,05)$ e, para $H 8141$ e H 8396 (tolerantes e pouco produtivos), $r=0.12$ (não significativo). Isso indica que, para se obterem informações corretas no melhoramento do cafeeiro visando à tolerância à seca, é necessário que se leve 
em consideração o acúmulo de dados de produção, os quais, segundo FAZUOLI (1977), devem ser de, pelo menos, seis a oito anos.

Os quadros 4, 5 e 6 apresentam, respectivamente, os dados de produção dos experimentos EP 260, EP 237A e EP 237B, relativos às progênies consideradas de interesse para as presentes observações e a sua posição entre todas as progênies que compuseram o experimento correspondente.

Enquanto para o EP 132 a introdução $C$ 1110-10 originou os melhores níbridos, a partir de cruzamentos com Mundo Novo, no EP 260 (Quadro 4) isto ocorreu com Catuaí Vermelho. Destacou-se, neste experimento, a progênie $F_{2}$ $\mathrm{H}$ 8105-7, proveniente de sementes colhidas de uma das plantas de $\mathrm{H} 8105$ do EP 131, que é composto por híbridos entre C 1110-10 e Catual Vermelho. Observa-se, também, que este híbrido foi o único de destaque que envolveu tais genótipos. Das hibridaçōes envolvendo linhagens de Mundo Novo e C 1110-10, uma série delas mostrou boas produções, destacando-se $H$ 3439-3, não comum ao EP 131 e EP 132. As progênies H 8114-3, H 8421-5, H 8420-6 e H 8107-7, originadas de sementes colhidas de plantas do EP 131 e EP 132, e que se posicionaram nestes experimentos entre as mais produtivas e tolerantes à seca, não tiveram o mesmo destaque no EP 260. Convém citar que no EP 260 estão incluídas progênies resultantes de hibridaçōes entre outros materiais genéticos e que estas se mostraram mais produtivas, mas não foram avaliadas quanto à tolerância à seca.

No EP 237A (Quadro 5), destacou-se o $F_{2}$ do híbrido $H$ 8484-1; apesar de não ser comum aos outros experimentos descritos, trata-se de uma população de hibridos entre Mundo Novo e C 1110-10. Ainda no EP 237A, a progênie H 8421-3 difere, de certa forma, das outras, principalmente sabendo que, na maioria, as progênies mais produtivas do experimento são seleções de terceira ou quarta geração de Catuai e Icatu de $C$. arabica.

No EP 237B (Quadro 6), a progênie $F_{2} H$ 8105-7, proveniente do EP 131 (H 8105), colocou-se como a segunda mais produtiva e resulta da hibridação de Catuai e C 1110-10. Sobressaem, também, neste experimento, as progênies $F_{2}$ $\mathrm{H} 8107-4$ e H 8107-9, originadas de H 8107 do EP 131, onde não foi muito produtiva, mas foi tolerante à seca. A progênie $F_{2} H 8421-3$ também aparece entre as de média produção do EP $237 \mathrm{~A}$, e originou-se de $\mathrm{H} 8421$ do EP 132 , onde pode ser considerada como a melhor progênie, mas o mesmo não é válido para sua descendência no EP 260.

Conclui-se que, segundo a análise desses experimentos, a introduçāo C 1110-10 da india (cultivar BA-10) esteve entre as mais promissoras para fins de seleção de cafeeiros tolerantes à seca, apresentando, em termos de produção, boas combinações com os cultivares Catuaí e Mundo Novo de $C$. arabica. As introduçōes C 1120-16 da Tanzânia (cultivar X321) e C 1521-2 da Costa Rica (cultivar BE-5) também podem ser consideradas promissoras, pois os híbridos descendentes de cruzamentos entre elas e Catuai posicionaram-se entre os mais produtivos e tolerantes ao deficit hídrico no EP 131. 


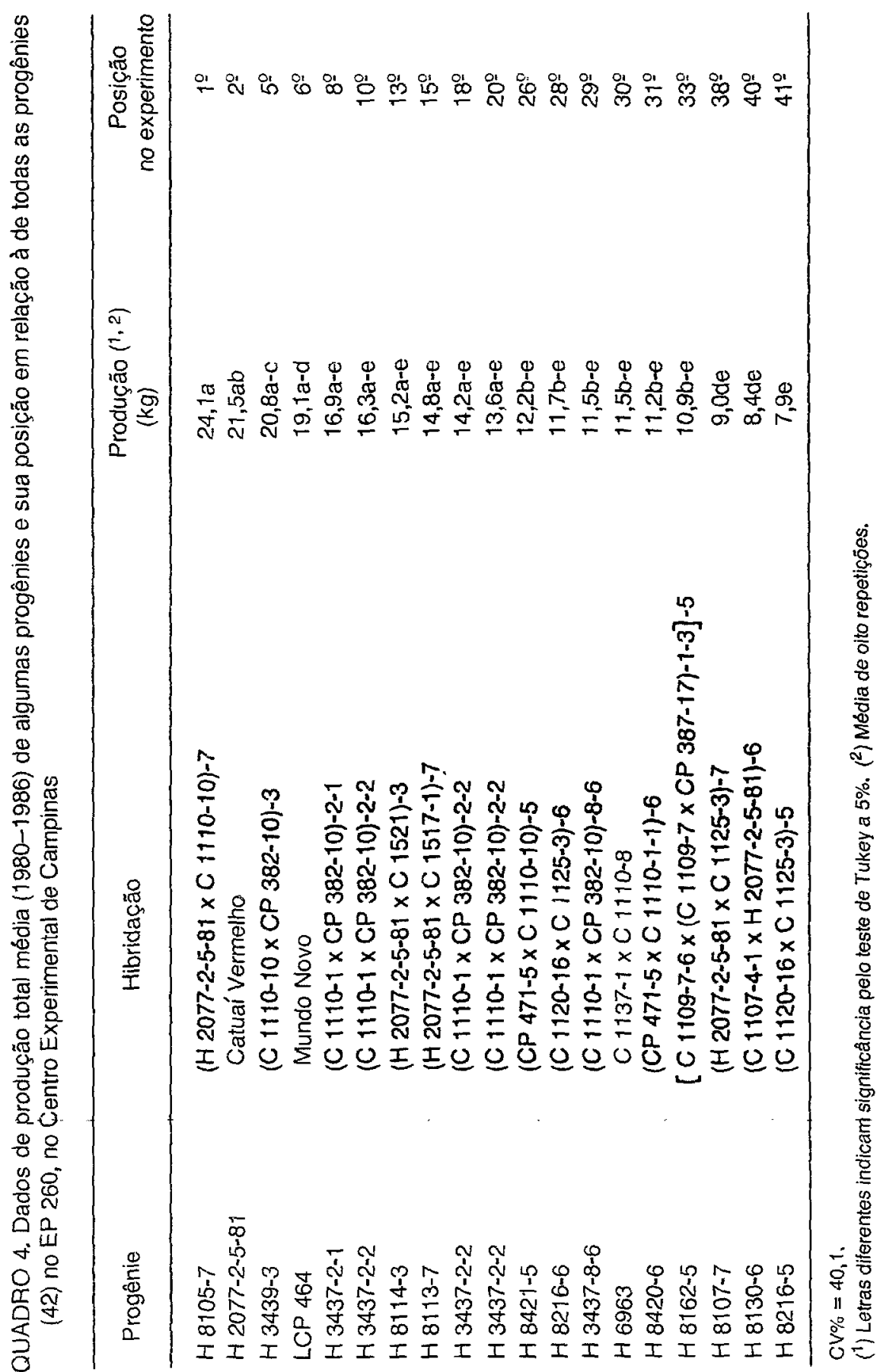


QUADRO 5. Dados de produção total média (1979-1984) de algumas progênies e sua posição em relação à de todas as progênies (121) no EP 237A, no Centro Experimental de Campinas

\begin{tabular}{|c|c|c|c|}
\hline Progênie & Hibridação & $\begin{array}{l}\text { Produçāo }(1,2) \\
(\mathrm{kg})\end{array}$ & $\begin{array}{c}\text { Posição } \\
\text { no experimento }\end{array}$ \\
\hline H 2077-2-5-81 & Catuaí Vermelho & $18,7 a-c$ & $3^{0}$ \\
\hline H 8484-1 & $(C P 471-5 \times C 1110-10)-1$ & $17,9 a-e$ & $5^{0}$ \\
\hline H 8421-3 & $(C P 471-5 \times C 1110-10)-3$ & $16,8 \mathrm{a}-\mathrm{g}$ & $9^{\circ}$ \\
\hline$H 8518-4$ & (CMP 386-2-4-9 x C 1110-1)-4 & $14,2 a-k$ & $29^{\circ}$ \\
\hline$H 8518-5$ & $($ CMP 386-2-4-9 x C 1110-1)-5 & $12,5 a-k$ & $36^{\circ}$ \\
\hline$C_{1110-10}$ & . Cultivar BA-10 da Índia & $9,5 b-1$ & $82^{\circ}$ \\
\hline H $8145-2$ & $(C 1109-3 \times C 1125-11)-2$ & $8,8 b-1$ & $88^{\circ}$ \\
\hline
\end{tabular}

$C V \%=47,5$.

(1) Letras diferentes indicam significância pelo teste de Tukey a 5\%. $\left({ }^{2}\right)$ Média de nove repetiçōes.

QUADRO 6. Dados de produção total média (1979-1984) de algumas progênies e sua posição em relação à de todas as progênies (42) no EP $237 \mathrm{~B}$, no Centro Experimental de Campinas

\begin{tabular}{|c|c|c|c|}
\hline Progênie & Hibridaçāo & $\begin{array}{l}\text { Produção }(1,2) \\
(\mathrm{kg})\end{array}$ & $\begin{array}{c}\text { Posição } \\
\text { no experimento }\end{array}$ \\
\hline H 8105-7 & $(\mathrm{H} 2077-2-5-81 \times C 1110-10)-7$ & $17,2 a b$ & $2^{0}$ \\
\hline$H 8518-9$ & $($ CMP 386-2-4-9 x C 1110-1-1)-9 & $14,8 a-d$ & $8^{0}$ \\
\hline LCMP $376-4-30$ & Mundo Novo & $11,3 a-d$ & $23^{\circ}$ \\
\hline H 8107-9 & $(\mathrm{H} \mathrm{2077-2-5-81 \times C} \mathrm{1125-3)-9}$ & $\uparrow 1,3 a-d$ & $24^{\circ}$ \\
\hline$H 8107-4$ & $(H$ 2077-2-5-81 x C 1125-3)-4 & $11,3 a-d$ & $25^{\circ}$ \\
\hline$H 8421-3$ & $(\mathrm{CP} 471-5 \times$ C $1110-10)-3$ & $11,0 a-d$ & $27^{\circ}$ \\
\hline$H 8126-9$ & (C 1107-4-1 x CP 474-4)-9 & $10,4 a-d$ & $30^{\circ}$ \\
\hline H 8518-5 & $(\mathrm{CMP} 386-2-4-9 \times \mathrm{C} 1110-1-1)-5$ & $10,4 a-d$ & $31^{\circ}$ \\
\hline$H 8089-4$ & $(H 2077-2-5-24 \times C 1137-5)-4$ & $10,0 b-d$ & $33^{\circ}$ \\
\hline H 8145-2 & (C 1109-3 x C 1125-11)-2 & $9,4 b-d$ & $34^{\circ}$ \\
\hline H 8113-5 & $(\mathrm{H} 2077-2-5-81 \times \mathrm{C} \mathrm{1517-1)-5}$ & $8,8 b-d$ & $38^{\circ}$ \\
\hline H 8142-7 & (C 1107-5-6 x C 1518-2)-7 & $8,3 b-d$ & $39^{\circ}$ \\
\hline $\mathrm{H} 8130-7$ & (C 1107-4-1 x H 2077-2-5-81)-7 & $6,8 c-d$ & $41^{\circ}$ \\
\hline H 8278-6 & $(C 1137-1 \times C 1518-2)-6$ & $4,8 d$ & $42^{\circ}$ \\
\hline
\end{tabular}

$C V \%=46,2$.

(1) Letras diferentes indicam significância pelo teste de Tukey a $5 \% .\left({ }^{2}\right)$ Média de nove repetiçōes. 
Apesar de ter-se indicado que o C 1110-10 apresentou melhor combinação com Mundo Novo, quanto à tolerância à seca e produção, não se pode excluir que o mesmo não ocorra entre esta introdução e o cultivar Catuaí VermeIho. Afirma-se isso porque, no EP 131, o número de cruzamentos entre ambos os cultivares é inferior ao encontrado no EP 132, entre C 1110-10 e Mundo Novo, impedindo a obtenção de maiores informações. Base para tal ressalva é o conhecimento de que no EP 260 e EP 237B, progênies derivadas do cruzamento entre C 1110-10 e Catuaí Vermelho destacaram-se entre as mais produtivas.

Os híbridos aqui mencionados vêm sendo investigados com maiores detalhes e, segundo MAZZAFERA et al. (1986), a introdução C 1110-10 mostra-se com características morfológicas e fisiológicas mais próximas às desejáveis para a tolerância à seca, quando comparada com o Catuaí Vermelho.

\author{
SUMMARY \\ YIELD AND DROUGHT TOLERANCE EVALUATION \\ OF COFFEE PLANTS (COFFEA ARABICA L.)
}

Progenies derived from crosses among India and Africa accessions and Catuai and Mundo Novo cultivars of Coffea arabica were evaluated as to yielding potential and drought tolerance, in two experiments located at the Experimental Center of the Instituto Agronomico, Campinas, State of São Paulo, Brazil. Yield data from 13 continuous harvests as well as from four-year-drought tolerance evaluations, revealed that the most promising drought tolerance sources were the accessions C 1110-10 (BA-10 cultivar - India), C 1120-16 (X321 cultivar - Tanzania) and C 1521-2 (BE-5 cultivar - Costa Rica). In such drought and yield evaluations it is very important to collect as many yield data as possible, since some progenies presenting drought tolerance showed low yield. Yield data from other experiments, related to the same progenies were also included and discussed.

Index terms: coffee tree, Coffea arabica L., drought tolerance, progenies.

\title{
REFERÊNCIAS BIBLIOGRÁFICAS
}

BOYER, J.S. Plant productivity and environment. Science, 218:443-448, 1982.

FAZUOLI, L.C. Avaliação de café Mundo Novo (Coffea arabica L.). Piracicaba, ESALQ/USP, 1977. 146p. Tese. (Mestrado)

GOLBERG, A.D.; BIERNY, O. \& RENARD, C. Évolution comparée des paramètres hydriques chez Coffea canephora Pierre et le hybride Coffea arabusta Capot et Ake soumis à deux cycles de sècheresse en conditions controlées. Café Cacao Thé, 28(4):257, 1984. 
JONES, H.G. Visual stimation of plant water status in cereals. Journal of Agricultural Science, 92:83-89, 1979.

JOSIS, P.; NDAYISHIMYE, V. \& RENARD, C. Études des relations hydriques chez Coffea arabica L. II. Evaliation de la résistance à la sécheresse de divers cultivars à Gisha (Burundi). Café Cacao Thé, 27(4):275-282, 1983.

MAZZAFERA, P. Estudo de resistência à seca em Coffea arabica. Relatório de Atividades de Pesquisa à Fundação de Amparo à Pesquisa do Estado de São Paulo. Campinas, 1984. 20p. (Mimeografado)

; TEIXEIRA, J.P.F. \& PISSOLATO, M.A.B. Análise de prolina visando seleção de cafeeiros (Coffea arabica) resistentes à seca. In:CONGRESSO BRASILEIRO DE PESQUISAS CAFEEIRAS, 13., São Lourenço, 1986. Resumos. p.18-19.

MEGURO, N.E. \& MAGALHĀES, A.C. Water stress affecting nitrate reduction and leaf diffusive resistance in Coffea arabica L. cultivars. Journal of the Horticultural Science, 58(1):147-152, 1983.

OROZCO-CASTAÑO, F.J. \& JARAMILLO-ROBLEDO, A. Efecto del deficit de humedad en el suelo sobre la temperatura del suelo y de las hojas en plantas de Coffea canephora y C. arabica. Cenicafé, 29(4):121-134, 1978.

ORTOLANI, A.A.; PINTO, H.S.; PEREIRA, A.R. \& ALFONSI, R.R. Parâmetros climáticos e cafeicultura. Rio de Janeiro, Instituto Brasileiro do Café, 1970. 27p.

O'TOOLE, J.C.; TURNER, N.C.; NAMUCO, D.P.; DINGKUHN, M. \& GOMEZ, K.A. Comparison of some crop water stress measurement methods. Crop Science, 24(6):1121$-1128,1984$.

RAMOS, L.C.S. \& LIMA, M.M.A. Crescimento do sistema radicular e da parte aérea em plantas jovens de cafeeiros. Bragantia, Campinas, 41:93-99, 1980.

SALISBURY, F.B. \& ROSS, C.W. Plant physiology. California, WadsWorth Publishing, 1978. Cap. 24, p.361-365.

THORNTWAITE, C.W. \& MATHER, J.R. The water balance. Centerton, New Jersey, 1955. 104p. (Publications in Climatology, v.III) 